\title{
Towards Industrial Strength Business Performance Management
}

\author{
Vadim Ermolayev ${ }^{1}$, Wolf-Ekkehard Matzke ${ }^{2}$ \\ ${ }^{1}$ Zaporozhye National Univ., Zaporozhye, Ukraine \\ vadim@ermolayev.com \\ ${ }^{2}$ Cadence Design Systems, GmbH, Feldkirchen, Germany \\ wolf@cadence.com
}

\begin{abstract}
Business performance management today does not possess a rigorous and grounded engineering methodology capable of delivering reliably measured values to backing up decision making. Much more it is the art of executive gurus who listen to their backbone experience and take their decisions using intuitive and heuristic approaches. This vagueness appears to be one of the main reasons for current dissatisfaction in industry. In this paper we express our vision of how a rigorous engineering methodology for business performance management in engineering design may look like. Our research work in PSI ${ }^{1}$ and PRODUKTIV $+^{2}$ projects strongly suggests that the underlying modeling framework has to be holonic. We consider that the solution has to: (i) be based on a sound Domain ontology of performance; (ii) use dynamic distributed planning technique and simulations to predict the performance of a design system; (iii) use the methodology which is sensitive to the specificities of a particular design system.
\end{abstract}

\section{Introduction}

Given the popularity of "performance" in modern society it is not surprising that performance management is very much en-vogue in virtually every area of human activity. Journalists, management consultants, and performance management solution providers alike seem to be overly excited by the topic. But performance management as a rigorous discipline is still in an embryonic state. In fact, "performance management as an identifiable subject for academic study and research arguably began in the mid-1990" [TB04]. We find myriads of papers on performance management, we find a significant and fast growing performance management market, but we don't find a mature, or even a suitably grounded framework of the non-linear management of performance. Despite significant research efforts, the result is not the shortly expected one. Probably the main reason for this unsatisfactory

${ }^{1}$ Performance Simulation Initiative (PSI) is the internal R\&D project of Cadence Design Systems, GmbH.

2 Reference System for Measuring Design Productivity of Nanoelectronic Systems (PRODUKTIV+) is the project partially funded by German Federal Ministry of Education and Research (http://www.edacentrum.de/produktivplus). 
situation is the highly interdisciplinary nature of performance management research, involving many fields of varying states of maturity and methodological practice. Disciplines that play a vital role in performance management research are for example: economics, engineering science, management theory, cultural anthropology, information technologies, psychology, education, artificial intelligence, philosophy, and so on. Additionally, there are professionals missing that are particularly skilled in integrating multiple research disciplines into a single required perspective. The metaphor of a holon comes to mind after saying that. Indeed, a mechanistic sum of skills required to solve performance management challenge does not give a satisfactory result. However, an intelligently collected (holonic) constellation of capabilities may bring us closer to the desired outcome.

In this paper we shall try to systematically describe the ingredients which, in their carefully combined proportion, may help in pursuing the solution. Indeed, the problem of performance management is that today it does not possess a rigorous and grounded engineering methodology capable of delivering reliably measured values to backing up decision making. Much more it is the art of executive gurus who listen to their backbone experience and take their decisions using intuitive and heuristic approaches ${ }^{3}$.

We are not that ambitious to envision an ultimate and a universal "philosopher stone" [Ma05] for any industry. Instead, we base the vision on our several year research and development experience in devising performance management methodology and intelligent tool support for engineering design in microelectronic and integrated circuits industry. All the statements of this paper are thereby applicable to engineering design performance in this industrial sector. Of course, the approach may seem generic enough to be applied in different domains.

The paper is structured as follows. Section 2 argues that performance management at strategic or executive level severely lacks important bits of the necessary knowledge to produce robust assessments. It is required to apply rigorous engineering approaches at design process level and simulate design system actions in order to proactively maintain its performance at the desired level. Section 3 is focused on the knowledge engineering aspect. Our approach to developing a descriptive Domain theory of performance is introduced. Section 4 expresses our views on how performance may be reliably measured based on the taken ontological approach. Section 5 sketches our vision of a performance engineering methodology based on the simulation of the performance of a design system. Section 6 provides concluding remarks and our vision of the future trends.

\section{Strategic Management versus Engineering Approach}

Today's trends in engineering design in microelectronics and integrated circuits show that mastering a new sub-micron technology slightly ahead of the competitors is not sufficient to feel yourself on the safe side. It is also required that your design system

\footnotetext{
${ }^{3}$ Of course it is stated that such methods are based on the assessments using Key Performance Indicators (http://en.wikipedia.org/wiki/Key_performance_indicators, checked on March 1, 2007).
} 
(denoted later in Section 3.3) demonstrates the "best-in-class" performance. Among the other performance "indicators" to be gained at a high level, a design system should be flexible and responsive enough to be capable of meeting and compensating sudden changes. For example, changing factors may be: time-to-market constraints, design specification, technology. Unpredicted distorting external influences like sudden reorganization of a design team, increased number of design activity iterations due to the changes in the quality requirements, or factual unavailability of a required resource may also influence a design system. Another important feature of a design system in the Era of glocalisation ${ }^{4}$ is the increasing geographical and cultural distribution bringing up new challenges to performance management. Indeed, provided that the parts of a design system are spread globally over time zones, the proper time management may substantially increase "round-the-clock" performance. If the particularities of local traditions and cultures are properly accounted for different groups the performance may be increased due to the savings in communication and synchronization overhead, etc.

Today's performance measurement and management practices are based mostly on strategic level benchmarking - finding a place of your company among the others on the industry sector bench. The prevailing methodology is the use of one or another sort of balanced scorecards [KN92]. Such a benchmarking, though providing reasonably sound indications of what is good or bad in terms of performance, does not help much in revealing the reasons. Moreover, these measures are based on the past and do not help predicting what will happen in the future. They also do not account for the changes in the business, its flexibility and the role of collaboration, which are important factors in engineering design performance. In order to make more grounded and predictive assessments, to engineer design performance at the required level, we have to apply the measures at the level of engineering design processes and use much finer grained bits of information for that. A negative consequence of taking this way in performance assessment and management is that the volume and the complexity of data to be processed are far too high to perform such an analysis by hand before the changes pass the point of no return. Therefore, a methodology and an intelligent software tool capable to automate such analyses is required as one of the important factors ensuring better performance of a design system.

The objective of the PSI and PRODUKTIV+ projects is to develop such a methodology and a tool capable to discover the "abyssal" reasons for the weaknesses of a design system and accounting for the pro-activity of human designers and the stochastic character of the external factors. The approach is to simulate a design system as a social and self-regulating team of autonomous actors having differing professional and cultural backgrounds. Hence, holonic principles become very relevant. One of the central points in modeling a design system is to adequately represent a designer as a locus of a goal-directed behavior and a design team as a dynamic social structure. A holon comprising actors, design teams, design tools in frame of an organization and possessing useful emerging properties of these combinations is used as an adequate model of a design system. Further on, a software agent can be naturally used as an appropriate implementation model for a designer

\footnotetext{
4 Glocalisation - a portmanteau of globalisation and localisation (http://en.wikipedia.org/wiki/Glocalisation, checked on March 1, 2007).
} 
and a multi-agent system (MAS) - as a model for an adaptable collaborative social structure like a design team or an organization at strategic management level.

\section{Towards the Notion and the Ontology of Performance}

"Performance" is one of the most prominent buzzwords today. For example, Google

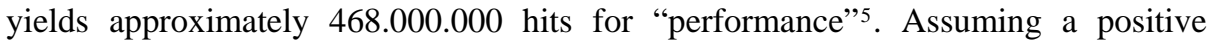
correlation between the number of hits on the World Wide Web and the importance of a concept in contemporary society, "performance" is definitely among the top terms used. To compare, the search for an undeniably important concept like "human" results in 467.000.000 hits 6 , which is slightly below "performance". So, "performance" is percept as a "materia prima" for human success or even existence.

Performance is everywhere and in everything one does - cradle-to-grave. There are seemingly countless word-combinations with the word "performance" in it. To give a glimpse of this, here are a few examples of what is available: high-performance baby wipes (from cradle!), kindergarten performance, performance school, performance university, performance bike, performance agreements, performance poetry, performance period, network performance, environmental performance, computer performance, performance objectives, performance agreements, performance appraisal, performance art, performance grave (to grave!)... So, why becomes "performance" that popular? And, being such an ultra-popular concept these days, doesn't "performance" become almost completely meaningless? If anything, what is it that people are trying to say when they speak of "performance"?

\subsection{The Notion of Performance}

Perhaps the definition of "performance" will lead to some hints. This, however, turns out to be a somewhat naive hope. More then ten years ago Meyer and Gupta [MG94] pointed out that there is "massive disagreement as to what performance is". A recent linguistic search and analysis of existing definitions of "performance" conducted in the PSI project highlights two main points: (i) there are many definitions of "performance" and new ones are continuously added; and (ii) "performance" definitions proffered by the performance proponents - whether from academia or industry - suffer from the lack of rigor and consensus. On the contrary, the trend towards opting for 'seductively vague' definitions continues unbroken to this day. A selection of few examples chosen from the vast supply of "performance" definitions is as follows.

Baldvinsdottir et al [Ba03]: "Performance is defined as carrying out tasks in a situation that allows optimal outcome." The issue that immediately arises with this definition is the exact meaning of "a situation that allows optimal outcome". Seemingly, the authors have chosen to employ a tautological conception of optimality. Under such a conception everything is adjusted to everything else given all relevant constraints. Saying that a situation allows for optimal outcome means that

\footnotetext{
${ }^{5}$ http://www.google.com.ua/search?q=performance, checked on March 1, 2007.

${ }^{6}$ http://www.google.com.ua/search?q=performance, checked on March 1, 2007.
} 
it allows exactly what it allows given all situational constraints. However, an important hint in this definition is that performance is tightly linked to carrying out tasks in an optimal way.

Faulk II [Fa02]: "Performance is defined as the accomplishment of job duties as required by the organization." This is a much too narrow definition. For example, what about any accomplishments above and beyond the required job duties? According to the above definition those accomplishments would not be attributed to "performance". However intuitively we know that this can't be the case. In fact, what is done above and beyond the job duties is often percept as a major contribution to "performance". Despite that, a hint that we shall collect is: an organization requires that tasks (arising of the job duties or beyond) are well-performed to optimize its own performance at a higher level.

Hall [Ha03]: "Performance is defined as the combination of competence in job skills and high levels of productivity." This attempt of a definition combines two disparate concepts - competence, which is a human ability and productivity, which is a neo-classical economic metric - into a single "mechanism" called "performance". What is the author trying to define here? A hint to answer might be: there are various sorts of performance aspects applicable to different parts of the puzzle. For example, a level of skill may characterize the performance of an actor, while productivity may be used as an integral performance characteristic of a process.

Melchert and Winter [MW04]: "Performance is defined as valued contribution to reach the goals of an organization." This is just another approach of defining "performance" that is seemingly both limited and inadequate. Who valuates a contribution? What happens if a contribution is not valued? From the above definition it follows that any contribution that is not considered to be a valued contribution - by whomever - does not add to performance. This will be true, regardless of the significance a contribution has to reach the goals of the organization. Isn't it too bad if it is just not valued? For example, if ten men months have been spent to find out that the development approach taken was a complete crap, was it good or bad performance? We tend to answer positively, though such an answer doesn't make assessments easier. A rational hint in this definition, however, is that a methodology of performance assessment needs to be based on a sort of a problem solving methodology.

O’Donnell and Duffy [OD02] suggest "In summary, the research in performance has been hindered by a lack of clarity on its meaning." We agree wholeheartedly with this statement, but there is always hope:

Harkema [Ha02]: "Performance is defined as a number or series of activities directed toward an outcome." This definition comes closest to encompassing all of the wide and varied sorts of "performance". Yet it is not perfect, as it contains the ambiguous phrase "number or series of". Furthermore, "directed" seem to indicate some "outside" control or intention. This is an unnecessary restriction, which results in a too-narrow definition of "performance".

In a situation like this, it is advisable to go back to the roots and use the etymology of "performance". In addition it is sensible to pin down dictionary definitions. This information can then be used as a framing device for denoting the concept of a performance in a comprehensive way. According to the Chambers Dictionary of Etymology [Ba88], "performance” was formed around 1500 AD from the English 
"perform" and the suffix "-ance". "Perform" is derived from the Old French "par" (completely) + "fornir" (to provide, furnish). The suffix "-ance" labels "performance" as a noun of action. As for the standard dictionary definitions we have: (1) the Oxford-English-Dictionary-Online" defines "performance" as "the action of performing" or "something performed", (2) the Meriam-Webster-Online Dictionary ${ }^{8}$ refers to "performance" as "the execution of an action", or "something accomplished", and (3) the American Heritage Dictionary" says "the act of performing", or "the state of being performed."

The etymology and the standard dictionary definitions of "performance" suggest that "performance" is derived from the root concept (or summum-genus) for intentional action. Therefore, we arrive at the following definition of performance: Performance is intentional action.

This definition of "performance", though too abstract and not much better than the one by Harkema, is valid under all circumstances and for all context-specific situations. However, all other "performance"-related concepts have to be defined as specialization of this root-concept. This is of central importance as the "performance" of something is always context based. More details will be given in Section 3.3. It should further be noted that not all actions are intentional. The notion of intentional action can be contrasted with accidental as well as with unintentional action.

\subsection{Performance Management}

Performance is intentional action. It is self-evident that any means, which supports the realization of intentions, is relevant in the context of performance. Management is said to be such a means. Therefore, performance should be managed. In a nutshell, this is what performance management is all about.

From the point of general concept, management has two basic dimensions. One, "linear management", centers on striving to continually improve practices and processes. Along this dimension, managers plan, budget, organize, staff, direct, supervise, control, etc. Linear management is solely applicable to situations of relative stability. For historical reasons (industrial society), most of the contemporary management knowledge is about linear management. An example for a linear management technique is Total Quality Management (TQM). The other dimension, "non-linear management", centers on coping with change. Along this dimension managers pro-actively respond to and anticipate change by aligning, motivating, and inspiring humans. Non-linear management has to be adaptive, whereas linear management is mainly plan-driven ("plan-pushed"). Non-linear management has to be "environmentally-pulled", that is, managers are directed more by responses to their environment than to a central command authority. Linear management prescribes what to do. Non-linear management enables how to determine what to do. Unmistakably, non-linear management is considerably more difficult than linear management. Examples for non-linear management techniques can be found under

\footnotetext{
${ }^{7}$ http://www.oed.com/, checked on March 1, 2007

8 http://www.m-w.com/, checked on March 1, 2007

${ }^{9}$ http://www.bartleby.com/61/, checked on March 1, 2007
} 
the topic of "agility" (the ability to perceive changes and establish appropriate techniques to cope with them).

Ubbesen ${ }^{10}$ provides the following metaphor to describe the significant difference between linear and non-linear management: "We could imagine that we have a line, and then we put a cross at one end and write the word problem. In accordance with our ordinary way of thinking, the word solution should consequently be placed at the other end. What do we do if the good solution is somewhere outside the line? As a matter of fact, creative consciousness is not bound to the line, it moves within a larger field of solution methods." Remarkably, this metaphor hints to look at the problem solving methodologies developed in Artificial Intelligence (AI).

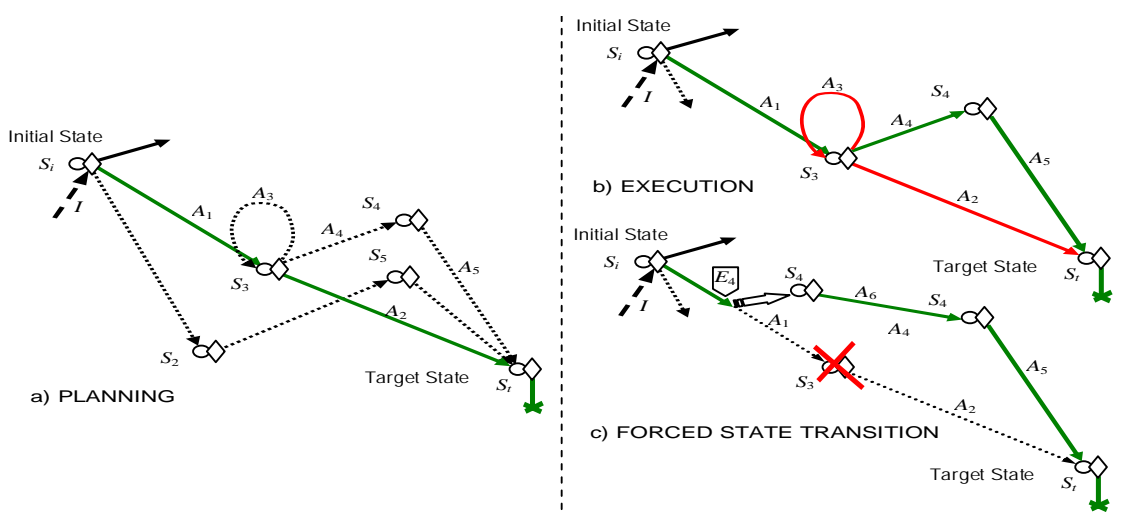

Fig. 1: Searching for the path with optimal performance in the solution space. The shortest arches stand for the best performance.

Indeed, if we would like to devise an optimal composition of design activities in a design process (Fig. 1) at planning phase, we most certainly risk to be mistaken. The combination of $A_{1}$ and $A_{2}$ (Fig. 1a) results in theoretically the shortest path $S_{i} \stackrel{A_{1}}{\longrightarrow} S_{3} \stackrel{A_{2}}{\longrightarrow} S_{t}$. However, the reality at execution phase may reveal that $A_{3}$ should be added several times before $A_{2}$ to improve the quality of results delivered by $A_{1}$ (Fig. 1b). In fact, it may well happen that a longer path skipped at planning, e.g. $S_{i} \rightarrow S_{2} \rightarrow S_{5} \rightarrow S_{t}$, may appear to be the optimal one with respect to performance.

A different continuation of the process instead of making iterations $\left(S_{i} \stackrel{A_{1}}{\longrightarrow} S_{3} \stackrel{A_{4}}{\longrightarrow} S_{4} \stackrel{A_{5}}{\longrightarrow} S_{t}\right)$ may in fact appear to be even more attractive. Another complication is the case when following the optimal planned path is no longer possible because of an external event forcing state transition (Fig. 1c). Both cases b) and c) require non-linear management methodology in order to be optimally resolved - dynamic re-planning, re-scheduling, possibly, design team reconfiguration, reaching agreements, coping with external events and other disturbances.

In today's business reality both management dimensions are present and necessary. However, the ratio between them is what makes the difference. Change was always with us, it always will be. But the pace and breadth of change may exceed the

${ }^{10}$ http://www.aaa.dk/aaa/ledelse-og_organisationsudvikling.eng.pdf, checked on March 1, 2007 
capability of linear response methods that worked before. That is linear management tends to "ignore" or "discourage" change until serious problems vent in a "volcanic eruption". With change more rampant today than ever, companies are required to utilize increasingly non-linear management techniques. However, the reality looks quite different. Most companies are "over"-managed in the linear sense and "under"led in the non-linear sense.

\subsection{Towards the Ontology of Performance}

For us now it seems evident that a rigorous description theory of the discussed Domain is necessary, though requires substantial knowledge engineering work. Again, Google returns around 23,400,000 hits for "performance management", but nothing (zero hits) for "performance management ontology". Though we are informed about the ongoing work on devising a formal ontology for performance management in the Semantic Web and Grid communities, today the field is mainly terra incognita for knowledge engineers. Some measurable factors of software system performance are outlined in [Le06]. A model of a Grid workflow performance has been proposed in [Tr04]. Consequently such a theory based on our work in PSI and PRODUKTIV+ may help us to denote the concept of performance more rigorously and in more detail than in the definition given above.

In engineering design, as outlined in Fig. 2, Performance ${ }^{11}$ is an intentional coordinated action targeted to pro-actively reaching the goals ${ }^{12}$.

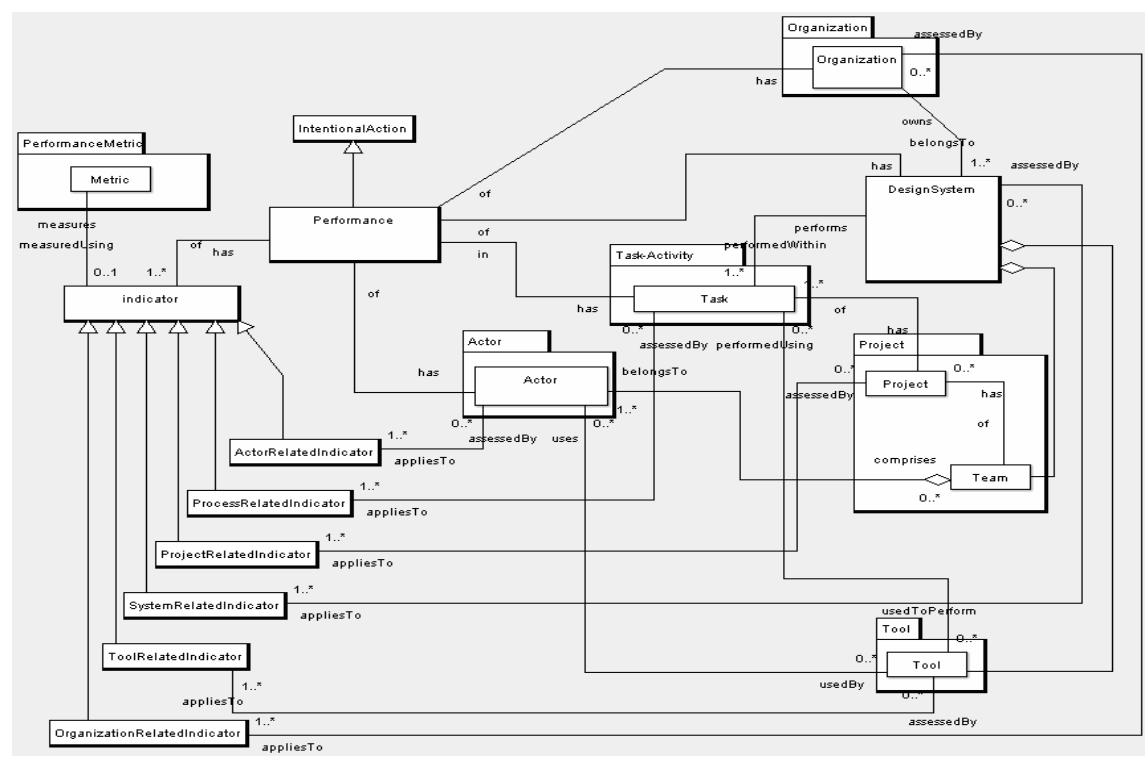

Fig. 2: An outline of Performance ontology

${ }^{11}$ Concept names are given with capitalized first letter.

12 An important point is that the goals pursued by different players: Actors, Teams, Organizations, may be coherent or conflicting. The parties have to reach agreements on their goals and to coordinate their actions to obtain better Performance. 
Performance is exhibited by an Organization. Performance is driving the execution of Tasks in design Projects. Performance is the inherent capability of Actors who form design Teams. A closely related concept is a Design System. In microelectronics a Design System is often understood as the configuration of a collection of software tools and IP libraries used in design processes to support them. We suggest broadening this simplified definition and consider a Design System a holonic system providing the environment in which design processes are performed. This environment comprises Actors rationally collaborating in design Teams, a normative framework providing regulations and policies, material resources, and Tools.

Performance is assessed using various Indicators. These Indicators may be taxonomized by their relationship to the concepts possessing Performance. For example, ActorRelatedIndicators are applied to assess Performance exhibited by Actors (like a skill level), ProcessRelatedIndicators are used to assess the Performance demonstrated in processes (like productivity), etc. Indicators have measurement rules associated with them - Metrics in Fig. 2. These rules may, however, be quite complex.

This outline of the performance ontology is grounded in the PSI Ontologies Suite [Er06] and relies on its formal definitions of the Domain o dynamic engineering design processes structured in Task-Activity, Actor, Resource, and Project ontologies.

\section{Measuring Performance}

Today's industrial performance management frameworks are based on the strategiclevel analysis of the carefully collected practices. They use statistical methods and knowledge mining techniques to devise the heuristics further on applied to coining out their performance indicators. It proves to be rather efficient for answering some important questions. For instance, a company's performance may be compared to the collected practices with quite a good ratio of statistical correlation if the knowledge base of these good and bad practices is sufficiently representative. According to the performance management literature (e.g., [Ca04]), the most popular frameworks for performance measurement and management (PMM) are Balanced Scorecards, Business Excellence Model, Performance Prism. In microelectronic and integrated circuits design a popular methodology is the one by Numetrics [Co04]. The method of all these approaches to assess performance is the way to measure the abovementioned indicators. However, even if the knowledge of performance indicator metrics is properly defined and managed (which is unfortunately not the case), such a high-level heuristic benchmarking approach does not help much in understanding the reasons of the strengths and weaknesses of a design system. The simulation of the behavior of a design system may be more helpful. Suppose, there is a way to simulate designer teams executing design projects in a design system, Suppose also, such a simulation may inject sudden disturbing influences in a process. Measuring simulated performance in such settings may to a certain extent be considered as a prediction of the real design system behavior in a similar environment. Such a prediction may hint what are the weak points in a design system. Of course the model used in simulations should be calibrated to more precisely reflect the peculiarities of the system under analyses. Fine grained knowledge of the previously performed actions may be used 
for the calibration. Generally, a similar approach is applied in devising trend lines for stocks and financial markets.

Let's observe how simulated performance may be assessed using the example of productivity. Productivity by its very nature is one of the most important economic metrics of performance and is defined by the ratio of the produced output (value) to the consumed input (value). As such, it is an integral characteristic of any transformation process. This neo-classical definition of productivity imposes rigid requirements on the process under consideration. The homogeneity of inputs and outputs is the most severe one with respect to engineering design. Known productivity measurement methodologies in engineering design are based on the assessment of design complexity characteristics in the creation of homogeneous input- and outputmeasures. They do it by applying heuristic weights to compared parameters (e.g., normalized transistor count ${ }^{13}$ in Semiconductor and Electronic Systems (SES) design, FP, KSLOC counts ${ }^{14}$ in software design). The fundamental problem of this approach is that complexity characteristics need to be invariant both to the type of a process and to the transformed design artifact. If those characteristics are not invariant, measurement scales tend to lack well-defined units. Consequently the properties of the measurement scale, the labeling of the units, and the interpretation of the values derived are of very limited practical use. Furthermore, in non-deterministic environments, like a design system, such measures are not very reliable, even if proposed. It is therefore important to build a measure which addresses the homogeneity requirement with respect to inputs and outputs and which is invariant to the dynamic characteristics of a process. Such a measure may be based on the integral process utility indicators like for example the ratio of the Earned Value to the Planned Value or to the Actual Cost at a Sign-off Stage. This implies that productivity of a design process may be assessed by the utility asset produced and accumulated by designers in a team. The more utility produced by a designer - the more relatively productive he or she is. Hence, more productive designers are characterized by the higher volume of accumulated Units of Welfare (UoW). It is assumed in PSI modeling framework that designers receive incentives adequately to their produced value. UoW earning and spending mechanisms in PSI are based on contracting deals stricken in several types of negotiations [EK06].

\section{Towards Performance Measurement and Management Methodology}

Krause [Kr03] has analyzed the following weaknesses of the contemporary performance management (PM) approaches pointing to them as to the reasons of dissatisfaction in industry: (i) strategic PM approaches are driven by "lagging" but not "leading" measurement methods; (ii) resulting PM methodologies and systems tend to be static ${ }^{15}$; (iii) there is a significant "abstraction" gap between strategic PM

\footnotetext{
${ }^{13}$ Measuring IC and ASIC Design Productivity. White Paper. Numetrics Management Systems, 5201 Great America Parkway, Suite 320 Santa Clara, CA 95054, 2000

${ }^{14}$ FP stands for Functional Point, KSLOC - for kilo lines of source code.

15 ... and linear
} 
approaches and available knowledge acquisition and representation methodologies; (iv) PM is traditionally based on rigid organizational structuring but not on desired properties of the required business processes; (v) the "metrics" are not transparent, are vague and do not clearly reveal the method of measurement and the sources of data. Our experience suggests adding: (vi) the role of a human designer and his pro-active collaboration in a design team is neglected; (vii) existing frameworks do not allow revealing the "abyssal" reasons for the weaknesses of a design system. Answering "why" questions requires a sort of a paradigmatic shift in modeling and assessing a design system and the design processes performed. In addition to building and measuring high-level heuristic performance indicators we need to acquire and use a deeper knowledge about the processes and their performers to make the assessments more justified. These bits of knowledge should cover engineering design processes and their support by technical, human, and organizational components comprising the aspects of design complexity, designers' competencies and abilities, concurrency and iteration of design tasks, dependencies, interfaces and collaboration effects at required level of detail.

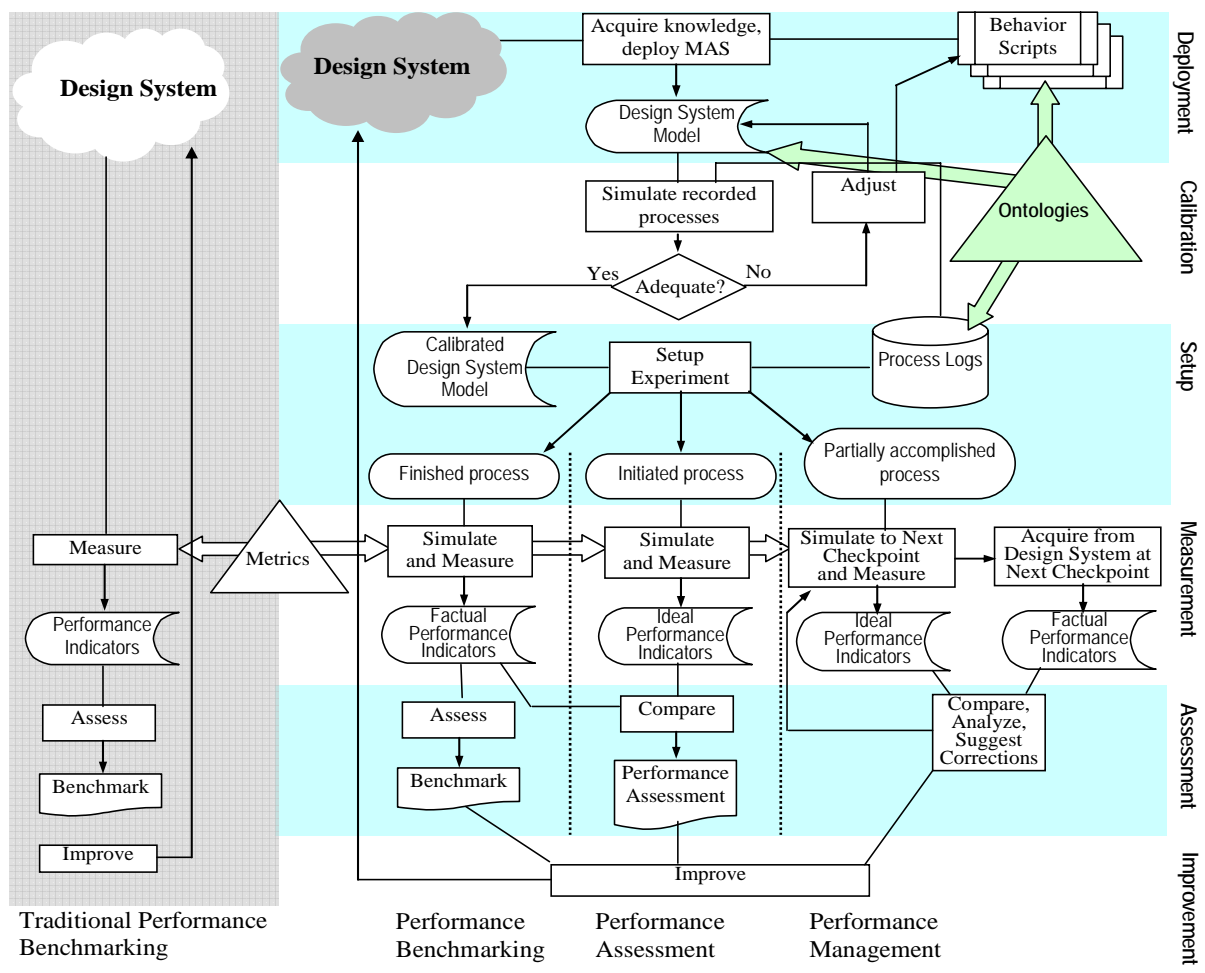

Fig. 3: Performance Measurement and Management Methodology in PSI and PRODUKTIV+ (simplified) compared to traditional frameworks.

Fig. 3 shows the differences in performance management methodologies. Traditional ones are applied at strategic management level. The Performance Measurement and Management Methodology $\left(\mathrm{PM}^{3}\right)$ we develop in PSI and 
PRODUKTIV+ occupies the niche between business and project management layers. $\mathrm{PM}^{3}$ uses agent-based design process simulation as its basic method. One of the topical distinctions of $\mathrm{PM}^{3}$ is that the model of a design system is calibrated before performance assessments are done. Calibration is the adjustment of the model by accounting the specifics of the design system. It is performed in the series of simulations of design processes. Using simulation allows us conducting the following kinds of experiments: (i) performance benchmarking based on the full records of the accomplished design processes; (ii) performance assessment based on the comparative analysis of the ideally simulated process performed by the team of agents and the record of the same process in real life; (iii) performance management based on the incremental simulation and comparison to what happens in the managed real life design process. The latter two modes allow us to understand why a real life process demonstrated worse performance than the corresponding ideal one, to verify if the process is stable with respect to different kinds of disturbing influences by injecting these influences in simulations, and to suggest grounded improvement recommendations for the design system. Evidently, $\mathrm{PM}^{3}$ and the prototype software tool require a domain model which is much more detailed than a traditional one. ontologies [Er06] play a central role in it. Fig. 3 shows that ontologies are intensively exploited in $\mathrm{PM}^{3}$. They provide formal specifications of the domain used in agent behavior scripts, design process records, the specification of a design system.

In order to obtain a qualitative assessment of a design system performance by simulation [Go06], we use the acquired knowledge and data [So06] to represent a design process in a procedural way accounting for a high degree of process dynamics [Er06].

\section{Concluding Remarks}

In this paper we expressed our vision of how an engineering methodology may be devised and applied to performance assessment and management in microelectronic engineering design. We stressed that engineering approach is required to make industry satisfied with its performance management methodology. The approach we suggest has to combine the contributions from different disciplines. Knowledge engineering provides a rigorous Domain theory in the form of performance ontology. Distributed artificial intelligence contributes with the agent-based software engineering methodologies and the theoretical foundation for distributed dynamic planning and scheduling. Management science draws the frames for the understanding how the key performance indicators may look like and provides the requirements for an industrial strength performance measurement and management methodology. We also advocate the simulation approach for performance management capable of making predictive analyses of a design system. The weakest spot in the outlined methodology is still performance metrics. It remains one of the main focuses of the ongoing research in PSI and PRODUKTIV+ projects. 


\section{References}

[Ba88] Barnhart, R. K. (Ed): Chambers Dictionary of Etymology. Chambers Harrap Publishers Ltd, Edinburgh, 1988

[Ba03] Baldvinsdottir, G. et al.: The Role of Trust in Accounting Research. In: Proc. $26^{\text {th }}$ Annual Congress of the European Accounting, Apr. 2-4, 2003, Seville

[Ca04] Carlucci, D., Marr, B., and Schiuma, G.: The Knowledge Value Chain: How Intellectual Capital Impacts on Business Performance. Int. J. Technology Management, 27(6,7): 575-590, 2004

[Co04] Collett, R.: Benchmarking IC Development Capability - What to Measure? Fabless Forum. Fabless Semiconductor Association, 11(2), 2004

[EK06] Ermolayev, V. and Keberle, N.: A Generic Ontology of Rational Negotiation. In: Karagiannis, D., Mayr, H.C. (eds.): Information Systems Technology and its Applications. $5^{\text {th }}$ Int. Conf. ISTA'2006, May 30-31, Klagenfurt, Austria, LNI Vol. 84. Gesellschaft für Informatik, Bonn (2006) 51 - 66

[Er06] Ermolayev, V., Jentzsch, E., Karsayev, O., Keberle, N., Matzke, W.-E., Samoylov, V., and Sohnius, R.: An Agent-Oriented Model of a Dynamic Engineering Design Process. In: Kolp, M., Bresciani, P., Henderson-Sellers, B., and Winikoff, M. (Eds.): Agent-Oriented Information Systems III. $7^{\text {th }}$ Int Bi-Conf Workshop, AOIS 2005, Utrecht, Netherlands, Jul. 26, 2005, and Klagenfurt, Austria, Oct. 27, 2005. Revised Selected Papers, 168-183, 2006

[Fa02] Faulk II, L. H.: Pay Satisfaction Consequences: Development and Test of a Theoretical Model. Dissertation, Louisiana State Univ., 2002

[Go06] Gorodetsky, V., Karsayev, O., Konushy, V., Jentzsch, E., Matzke, W.-E., and Ermolayev, V.: Multi-agent Software Tool for Management of Design Process in Microelectronics. In: Nishida, T., Klusch, M., Sycara, K., Yokoo, M. (Eds.): Proc. IEEE/WIC/ACM Int. Conf. on Intelligent Agent Technology (IAT-06), 18-22 Dec., 2006, Hong Kong, pp. 773-776

[Ha02] Harkema, S.: Reflections on the consequences of the application of complexity theory for new product introductions. In (Frizelle, G.; Richards, H. Eds.): Tackling industrial complexity: the ideas that make a difference. Papers from the 2nd Int. Conf. of the Manufacturing Complexity Network, U of Cambridge, UK 9-10 April 2002, pp. 467-482

[Ha03] Hall, D.: Power Strategy Tool Kit - Part 2: Managing the performance. Learning \& Leading with Technology, 31(2):36-41, 2003.

[KN92] Kaplan, R.S. and Norton, D.P.: The balanced scorecard: measures that drive performance. Harvard Business Review, Jan - Feb: 71-80, 1992

[Kr03] Krause, O.: Beyond BSC: a process based approach to performance management. Measuring Business Excellence, 7(3): 4-14, 2003

[Le06] Lera, I., Juiz, C., and Puigjaner, R.: Performance-related ontologies and semantic web applications for on-line performance assessment of intelligent systems. Science of Computer Programming, 61: 27-37, 2006

[Ma05] Matzke, W.-E.: Engineering Design Performance Management - from Alchemy to Science through ISTa. In: Kachek, R., Mayr, H., Liddle, S. (Eds.) $4^{\text {th }}$ Int Conf on Information Systems Technology and its Applications, ISTA 2005, 23-25 May, 2005, Palmerston North, New Zealand, 154-179, 2005

[MG94] Meyer, M. W. and Gupta, V.: The Performance Paradox. In (Cummings, L. L.; Staw, B. Eds.): Research in organizational behavior. JAI Press, Greenwich, Conn., 1994, 309-369

[MW04] Melchert, F. and Winter, R.: The Enabling Role of Information Technology for Business Performance Management. In (Meredith, B.; Shanks, G.; Arnott, D.; Carlsson, S. Eds.): Decision Support in an Uncertain and Complex World, Proc. 
2004 IFIP Int. Conf. on Decision Support Systems (DSS2004), Prato, Italy, 2004, pp. 535-546

[OD02] O'Donnell, F. J. and Duffy, A. H. B.: Modelling design development performance. Int. J. of Operations \& Production Management, 22(11):1198-1221, 2002

[So06] Sohnius, R., Ermolayev, V., Jentzsch, E., Keberle, N., Matzke, W.-E., and Samoylov, V.: Managing Concurrent Engineering Design Processes and Associated Knowledge. In: Ghodous, P., Dieng-Kuntz, R., and Loureiro, G. (Eds.): Leading the Web in Concurrent Engineering. Proc. $13^{\text {th }}$ ISPE Int Conf on Concurrent Engineering: Research and Applications, 18-22 Sept., Antibes, French Riviera, IOS Press, Series: Frontiers in AI and Applications, Vol. 143, pp. 198-205, 2006

[TB04] Thorpe, R. and Beasley, T.: The characteristics of performance management research - Implications and challenges. International Journal of Productivity and Performance Management, 53(4): 334-344, 2004.

[Tr04] Truong, H.-L., Dustdar, S., and Fahringer, T.: Performance Metrics and Ontologies for Grid Workows, technical report TUV-1841-2004-28, Technical University of Vienna, 20 Sept., 2004 